\title{
A ESQUERDA RADICAL NO PERÍODO PÓS-2009: NADA DE (MUITO) NOVO EM PORTUGAL?
}

\section{THE RADICAL LEFT IN THE POST-2009 PERIOD: NOTHING (VERY) NEW IN PORTUGAL?}

DOI: http://dx.doi.org/10.15448/2178-3748.2016.1.22961

\author{
José Santana Pereira \\ Doutor em Ciências Políticas e \\ Sociais pelo Instituto Universitário \\ Europeu em Florença \\ E-mail: jose.pereira@ics.ul.pt
}

\begin{abstract}
RESUMO: A crise económica que eclodiu nas democracias europeias periféricas a partir de 2009 teve, em vários países da Europa do Sul, consequências graves em termos de estabilidade governativa e dos sistemas partidários. Neste contexto, o caso português tem sido apontado como excecional, visto que o agravamento da situação económica e as suas consequências políticas não provocaram uma afirmação eleitoral sem precedentes de forças de esquerda radical (como na Espanha e na Grécia). Neste artigo, apresenta-se o panorama da esquerda radical em Portugal e procede-se à análise de algumas dimensões associadas a este fenómeno de maior estabilidade do sistema partidário português à esquerda, nomeadamente a ausência de um fenómeno SYRIZA ou Podemos, recorrendo a explicações de natureza económica, ligadas à cultura política e à natureza do sistema partidário consolidado nas últimas quadro décadas.
\end{abstract}

PALAVRAS-CHAVE: Esquerda radical; Portugal; Crise europeia

ABSTRACT: The outbreak of the economic crisis in the peripheral European democracies from 2009 onwards had, in several Southern European countries, considerable consequences in terms of government and party system stability. In this context, the Portuguese case has been singled out as exceptional, since the worsening of the economic situation and its political consequences did not lead to the unprecedented electoral rise of radical left political forces, as in Spain and Greece. In this article, I present the Portuguese panorama in terms of radical left and analyse some of dimensions that allow us to understand this higher stability of the Portuguese party system to the left and the absence of a Podemos or SYRIZA phenomenon, namely economic factors, political culture, and the nature of the party system that was consolidated in the last four decades.

Keywords: Radical left; Portugal; European crisis

\section{INTRODUÇÃO}

Em vários países da Europa do Sul, os últimos anos têm sido tumultuosos em termos económicos e financeiros. A crise das dívidas soberanas levou a uma deterioração da situação económica na Grécia, Portugal e Irlanda, mas também em Espanha e Itália, com o agravamento das contas públicas, a estagnação do crescimento e/ou recessão e um aumento das taxas de desemprego. No primeiro conjunto de países, foi necessário recorrer a um 
bailout, ou pedido de resgate financeiro, negociado com as instituições internacionais comummente designadas por troika (Banco Central Europeu, Comissão Europeia, Fundo Monetário Internacional), ${ }^{1}$ que, por sua vez, resultou na implementação de medidas de austeridade duras e incisivas. Esta crise teve consequências políticas indiscutíveis (BOSCO e VERNEY, 2012; MAGALHÃES, 2014a). Sabe-se que os eleitores tendem a premiar os governos que fomentam o crescimento económico, favorecendo a vitória eleitoral do partido ou partidos que o compõem, enquanto que em tempos de desaceleração ou degradação da situação económica, os governos tendem a ser punidos (LEWIS-BECK e STEGMAIER, 2000; LEWIS-BECK e PALDAM, 2000). Num cenário de forte crise económica como a que afetou os países mais periféricos da União Europeia, era expectável que a punição dos partidos responsáveis pela gestão económica do país fosse exponenciada (BARTELS, 2012; VASSELAI e MIGNOZZETTI, 2012; HERNANDEZ e KRIESI, 2016).

De facto, foi isto que aconteceu na generalidade destes países. Os anos que se seguiram ao eclodir da crise foram de némesis na política europeia (BOSCO e VERNEY, 2012), ou seja, de extrema punição dos partidos que estavam no governo no momento em que situação financeira se agravou. Em Portugal, o governo de Sócrates foi apenas ligeiramente punido pelo eleitorado em 2009, ano em que a dimensão da crise vindoura era ainda desconhecida e em que se atribuíam os primeiros sinais da crise a fatores externos à governação socialista (FREIRE e SANTANA-PEREIRA 2012). No entanto, em 2011 as coisas mudam para o Partido Socialista (PS): depois do mau resultado nas presidenciais de janeiro e do pedido de demissão do seu primeiro-ministro, as legislativas de junho trouxeram uma pesada derrota - um dos piores resultados do partido em eleições legislativas - resultante em grande medida de uma avaliação negativa do desempenho do governo. Em 2011, quanto mais os eleitores pensavam que a responsabilidade da situação económica era exclusivamente do governo (vis-à-vis as instituições europeias, a crise internacional ou as agências de rating), maior probabilidade tinham de votar no principal concorrente do PS (MAGALHÃES, 2012, 2014b; ver também FREIRE e SANTANA-PEREIRA, 2011).

Também em 2011, uma acentuada derrota do incumbente é observada na Irlanda e na Espanha - ainda que a punição do partido no governo tenha sido bastante mais drástica no caso irlandês (MARTÍN e URQUIZU-SANCHO, 2012; MARSH e MIKHAILOV, 2014; TORCAL, 2014). Na Grécia e na Itália, os governos eleitos são substituídos por governos

\footnotetext{
${ }^{1}$ A Espanha também pediu um resgate, mas de natureza diferenciada, focado exclusivamente no setor bancário. Para uma análise mais detalhada da situação económica nestas democracias ver, por exemplo, BOSCO e VERNEY (2012) e FREIRE et al. (2014).
} 
chefiados por tecnocratas (Papademos e Monti) que contam com o apoio de maiorias alargadas nos parlamentos: nos dois casos, convocar eleições era visto como demasiado arriscado para as finanças nacionais. Em 2012, o Movimento Socialista Pan-Helénico (PASOK), um dos pilares do sistema partidário grego, é fortemente punido nas eleições (TSATSANIS e TEPEROGLOU, 2014), vindo a tornar-se virtualmente irrelevante em $2015^{2}$ (TSIRBAS, 2015). Por sua vez, em Itália as eleições de 2013 são marcadas pela fraca prestação do novo partido criado por Monti (Escolha Cívica) e pela perda de votos e assentos por parte dos partidos que garantiram apoio parlamentar ao governo técnico, Partido Democrático (PD) e Povo da Liberdade (PdL) (BELLUCCI, 2014).

Ao mesmo tempo, em Espanha e na Grécia, observa-se a criação e/ou o crescimento eleitoral exponencial de partidos ou coligações de esquerda radical definidos como populistas (STAVRAKAKIS e KATSAMBEKIS, 2014; KIOUPKIOLIS, 2016), que abraçam posições anti-austeritárias e são muito críticos em relação ao papel da União Europeia na gestão da crise. ${ }^{3}$ Na Grécia, a Coligação da Esquerda Radical (SYRIZA), criada em 2004, passou de 5 por cento em 2009 para cerca de 36 por cento em janeiro e setembro de 2015, assegurando o controlo do governo grego (ainda que em coligação com um pequeno partido nacionalista de direita, cujo posicionamento no eixo pró/anti-UE o aproxima do SYRIZA; TSIRBAS, 2015). Por sua vez, em Espanha, se as eleições de 2011 foram apenas marcadas pela derrota do incumbente Partido Socialista Operário Espanhol (PSOE) ${ }^{4}$ e pela vitória do Partido Popular (PP), a partir de 2014 o panorama muda consideravelmente, com a afirmação eleitoral de um partido que nasce no rescaldo da indignação pela crise e pela austeridade, o Podemos (8 por cento nas europeias de 2014, 14 por cento nas regionais de 2015, 21 por cento nas legislativas de 2015) e, em menor grau, de um partido de centro (Cidadãos).

Em suma, na Grécia, o sistema partidário, um dos mais estáveis da Europa, implodiu (TSATSANIS e TEPEROGLOU, 2014) e deu lugar a um sistema em que um dos principais elementos é um partido/coligação de esquerda radical, enquanto que em Espanha o bipartidarismo tem os dias contados (ROMÃO 2015), devido à afirmação do Podemos e, em menor medida, do partido de centro Cidadãos. Em Portugal, nada disto aconteceu. Por um

\footnotetext{
${ }^{2}$ O PASOK passou de incumbente a parceiro minoritário de um governo liderado pelo Nova Democracia (ND), e em janeiro de 2015 ficou em sétimo lugar nas eleições, conseguindo menos de 5 por cento dos votos.

${ }^{3}$ Um fenómeno similar ocorreu em Itália, com o Movimento Cinco Estrelas (M5S) a tornar-se num dos partidos eleitoralmente mais importantes na eleição de 2013, a par (ou até mesmo à frente) dos principais partidos de centro-esquerda (PD) e centro-direita (PdL). No entanto, ao contrário do Podemos ou do SYRIZA, o M5S não é um partido de esquerda, visto ter eleitores tanto de esquerda como de centro-direita (DIAMANTI, 2014), sendo mais consensualmente categorizável como partido populista, antipolítica e anticasta.

${ }^{4}$ A punição do PSOE continua nas europeias de 2014 (23 por cento dos votos, menos 16 pontos percentuais em relação a 2009) e nas legislativas de 2015 (22 por cento, menos 7 pontos percentuais em relação a 2011).
} 
lado, a punição do principal partido de centro-esquerda nunca foi tão grave quanto a observada na Grécia ou em Espanha. O PS não desce abaixo dos 28 por cento de votos (2011), e em 2015 chega mesmo a disputar o primeiro lugar com a coligação incumbente formada pelo Partido Social Democrata (PSD) e pelo CDS-Partido Popular (CDS-PP), terminando, contudo, em segundo lugar, com 32 por cento dos votos, menos 5 que a coligação (DE GIORGI e SANTANA-PEREIRA, 2016). Por outro, e acima de tudo, não há um crescimento exponencial da esquerda radical após o início da crise. Os resultados eleitorais do partido comunista conservador, de extrema-esquerda (MARCH 2012), Partido Comunista Português (PCP), apresentam grande estabilidade nos últimos 25 anos, ${ }^{5}$ inclusive nas eleições que tomam lugar depois do início da crise da dívida soberana. Já os partidos da denominada esquerda radical (MARCH 2012), ou apresentam nas últimas três eleições legislativas (2009, 2011, 2015) um percurso errático, com subidas e descidas pronunciadas mas resultados sempre iguais ou inferiores a 10 pontos percentuais (Bloco de Esquerda - BE), ou demonstram-se incapazes de se afirmar eleitoralmente, não elegendo deputados (Livre e Movimento Alternativa Socialista - MAS).

Em linhas gerais, apesar do contexto de profunda crise económica e financeira, o sistema partidário português manteve-se, na sua essência, bastante intacto. Há, a partir das legislativas de 2009, uma tendência no sentido do abandono da rota bipartidária que caracteriza a política portuguesa a partir de 1987, mas trata-se de uma tendência já observada nas europeias do mesmo ano e, de um certo ponto de vista, as eleições de setembro de 2009 são ainda eleições pré-crise. ${ }^{6} \mathrm{O}$ sistema partidário é, quer em termos dos principais partidos que o compõem, quer em termos das relações de força entre estes, muito similar em 2009, 2011 e 2015, com os dois principais partidos a obter cerca de dois terços dos votos, o número efetivo de partidos eleitorais a aproximar-se de 4 e um número efetivo de partidos parlamentares próximo de 3 (LISI, 2015). A estabilidade e resiliência do sistema partidário português na segunda década do século XXI, em comparação com as fortes convulsões nos outros países afetados pela crise (Irlanda, Grécia, Espanha, Itália), com a redução da importância eleitoral de partidos tradicionais e o aparecimento/fortalecimento de várias organizações partidárias com um discurso de protesto (BOSCO e VERNEY, 2012; MARTÍN e URQUIZU-SANCHO, 2012; BELLUCI, 2014; TSATSANIS e TEPEROGLOU, 2014,

\footnotetext{
${ }^{5}$ Período em que o partido tem concorrido a eleições coligado com o Partido Ecologista "Os Verdes" (PEV).

${ }^{6}$ BOSCO e VERNEY (2012) identificam como ponto de viragem na Europa do Sul o anúncio do governo grego de que as contas para 2009, em termos de défice e dívida pública, seriam muito mais negativas do que o inicialmente previsto. Isto ocorre em outubro de 2009. No caso português, o pedido de resgate só acontece no primeiro semestre de 2011, já com o segundo governo Sócrates demissionário e eleições antecipadas marcadas.
} 
TSIRBAS 2015) é, sem dúvida, um fenómeno que distingue Portugal dos restantes países. Neste quadro de estabilidade, a par da manutenção da irrelevância eleitoral da extrema-direita, vale a pena destacar a ausência de um crescimento exponencial da esquerda radical, pré-crise ou pós-crise, enquanto elemento distintivo do caso português vis-à-vis as duas outras democracias da terceira vaga na Europa do Sul.

O objectivo deste artigo é o de elencar e avaliar alguns dos principais argumentos que têm vindo a ser utilizados para justificar a ausência de um fenómeno SYRIZA ou Podemos em Portugal no período entre a eclosão da crise económica e financeira nas democracias do sul da Europa (2009) e os dias de hoje. Começa-se por desenhar o panorama da esquerda radical no sistema partidário português, sendo que a análise recai sobre dois grupos: os partidos de esquerda radical que têm tido um papel importante na esfera política portuguesa ao longo das últimas décadas, nomeadamente através da sua presença no parlamento nacional, na delegação portuguesa no Parlamento Europeu e, num dos casos, ao nível do poder local (PCP e BE); e os novos partidos, criados após a crise das dívidas soberanas (MAS e Livre). ${ }^{7}$ A secção termina com uma análise comparativa do percurso eleitoral destes partidos no século XXI. Em seguida, analisam-se algumas dimensões potencialmente explicativas da ausência de um novo partido nascido das cinzas da crise e/ou de crescimento exponencial de um partido de esquerda radical nas urnas. $\mathrm{O}$ artigo termina com algumas considerações a respeito dos partidos de esquerda radical em Portugal após as eleições de outubro de 2015 e o estabelecimento de acordos com o PS.

\section{A ESQUERDA RADICAL EM PORTUGAL (2009-2015)}

A esquerda radical é composta pelos "partidos que se definem como estando à esquerda da, e não apenas na ala esquerda da social-democracia, considerando que esta última não é suficientemente de esquerda ou, até, que nem sequer é de esquerda" (MARCH, 2012, pp. 27-28). Inerente a esta definição está a ideia de radicalismo, que implica um corte, uma transformação e uma mudança do sistema político e económico vigente, mas não se opõe à

\footnotetext{
${ }^{7}$ Há um terceiro grupo de partidos de esquerda radical que este artigo não aborda: os micropartidos de esquerda radical, com décadas de existência e incapacidade reiterada de obter representação. O exemplo mais paradigmático é o maoista Partido Comunista dos Trabalhadores Portugueses - Movimento Reorganizativo do Partido do Proletariado (PCTP-MRPP), que, em setembro de 2015, chocou a sociedade portuguesa com a violência do slogan de campanha "Morte aos Traidores". O motivo que subjaz à exclusão do PCTP-MRPP e dos seus congéneres prende-se acima de tudo com o facto de que, olhando para o seu historial e para a sua estagnação ideológica, tais partidos dificilmente poderiam ser parte do crescimento da esquerda radical em Portugal no período pós-crise.
} 
democracia liberal nem aspira a uma revolução (MARCH, 2012). Os partidos de extremaesquerda são, de acordo com o autor, um subtipo dos partidos de esquerda radical, sendo distinguíveis por uma visão positiva da URSS e, nalguns casos, alguma animosidade em relação à democracia liberal e às suas instituições. Usando esta distinção dicotómica, seria fácil colocar o PCP, criado em 1921 e legalizado em 1974, nesta última categoria, e o BE, criado em 1999, na categoria dos partidos de esquerda radical strictu sensu. No entanto, o espetro da esquerda radical na Europa parece ser um pouco mais complexo. De facto, de acordo com MARCH (2012), existem cinco tipos de partidos que se cruzam com estas dicotomias: comunistas conservadores (como o PCP), comunistas renovadores/reformadores (como a Rifondazione Comunista em Itália), socialistas democráticos (como o BE e o SYN, o principal partido na base da formação do SYRIZA, mas também o Livre), socialistaspopulistas e social-populistas. A tipologia de GOMEZ, MORALES e RAMIRO (2016) é menos complexa, estabelecendo apenas uma diferenciação entre os partidos de esquerda radical tradicionais (entre os quais estão o PCP, mas, curiosamente, também o SYRIZA até 2009) e da nova esquerda (entre os quais se contam o BE).

Há, assim, na literatura especializada, acordo em relação ao facto de que o PCP e o BE são partidos significativamente distintos. Apesar da sua proximidade na dimensão ideológica esquerda-direita, são bastante diferentes em termos de vários aspetos programáticos (entre os quais a integração europeia, sendo o PCP bastante mais crítico da UE que o BE; FERNANDES e SANTANA-PEREIRA, 2014), características do eleitorado, organização interna, enraizamento na sociedade e historial eleitoral (para um resumo destas diferenças, ver FREIRE, 2012). O PCP foi criado em 1921, sendo um dos principais protagonistas da oposição ao regime ditatorial de Salazar e Caetano até 1974. Após assumir alguma preponderância nos processos políticos pós-autoritários, que incluiu a participação nos governos provisórios do período de transição democrática (1974-1976), o PCP não voltou a ter responsabilidades governativas ao nível nacional. Nos anos que se seguiram, foi sempre capaz de eleger vários deputados à Assembleia da República (obtendo, nos últimos 25 anos, resultados eleitorais muito estáveis, após uma ligeira quebra eleitoral temporalmente coincidente com o fim da URSS) e alguns deputados ao Parlamento Europeu, bem como de conseguir bons resultados nas eleições autárquicas, sendo o terceiro partido ao nível do poder local. ${ }^{8}$ Em 2015, o PCP estabeleceu um acordo com o PS destinado a viabilizar o governo minoritário deste partido de centro-esquerda.

\footnotetext{
${ }^{8}$ Quase sempre em coligação com partidos significativamente mais pequenos. Ver FREIRE (2012).
} 
Por sua vez, o BE foi criado em março de 1999 através da coligação de dois micropartidos (União Democrática Popular, Partido Socialista Revolucionário) e um movimento político (Política XXI); outros pequenos movimentos políticos e de cidadãos (entre os quais o FER/Ruptura, que havia de dar origem ao MAS em 2014) também se lhes juntaram. O primeiro teste eleitoral do BE aconteceu nas eleições europeias de 1999. Os resultados foram modestos, e o partido não conseguiu eleger nenhum eurodeputado. No entanto, alguns meses depois, nas legislativas de outubro, os números obtidos são mais favoráveis, e o BE entra no parlamento português. Sem surpresas, os dois deputados do BE foram eleitos pelo círculo de Lisboa - afinal, o eleitorado do partido era tendencialmente composto por jovens, de classe média, escolarizados e cosmopolitas (FREIRE, 2012), que não se reviam no conservadorismo do PCP ou no socialismo católico do PS de António Guterres. ${ }^{9}$ A década seguinte foi de crescimento para o BE, que passa de 2,4 por cento dos votos e 2 assentos parlamentares em 1999 para 9,8 por cento dos votos e 16 deputados em 2009 - um resultado superior ao do PCP. No entanto, o partido é severamente punido nas eleições antecipadas de 2011. É provável que isto se deva ao facto de a sua indisponibilidade para encontrar um entendimento com o PS (que contribuiu para a queda do governo Sócrates, o pedido de resgate e a eleição de um governo de direita) não ter agradado a parte do seu eleitorado. No entanto, em outubro de 2015, o BE renasceu das cinzas, conseguindo o seu melhor resultado eleitoral de sempre e ultrapassando (pela segunda vez) o PCP. O BE assinou também um acordo com o PS destinado à viabilização parlamentar do atual governo.

O sistema partidário português é relativamente estável em termos de dimensão (número efetivo de partidos eleitorais e de partidos parlamentares) e, acima de tudo, em termos do número e da identidade dos partidos que obtêm representação parlamentar aos níveis nacional e europeu (LISI, 2015; FREIRE, LOBO e MAGALHÃES 2007; ver também ALMEIDA e FREIRE 2005, SANTANA-PEREIRA 2010, ESPÍRITO SANTO 2010, FREIRE e SANTANA-PEREIRA 2011, 2015). Apesar disso, as tentativas de criação de novos partidos políticos são numerosas. Alguns destes novos partidos têm o propósito de constituir uma oferta política num quadrante ainda não ocupado por outros partidos (centrodireita liberal, por exemplo - veja-se o caso do Movimento Mérito e Sociedade, que em 2011 passa a designar-se Partido Liberal Democrata); outros desejam captar o voto dos abstencionistas (o recém-criado Nós Cidadãos) ou seduzir o eleitorado de outros partidos.

\footnotetext{
${ }^{9}$ Líder do PS entre 1992 e 2002 e primeiro-ministro entre 1995 e 2002. Após abandonar o cargo, na sequência do pedido de demissão em dezembro de 2001, foi Alto-comissário das Nações Unidas para os Refugiados (20052015). Atualmente é conselheiro de Estado e candidato a Secretário-geral das Nações Unidas.
} 
Entre 2009 e 2015, foram criados em Portugal dez novos partidos, mas somente dois são de esquerda radical. O ano eleitoral de 2009 leva à criação de três novas formações partidárias - o MEP (Movimento Esperança Portugal, atualmente extinto), o PTP (Partido Trabalhista Português) e o PPV/CDC (Portugal Pró-Vida/Cidadania e Democracia Cristã). Nenhum destes partidos é de esquerda radical (o PTP define-se como sendo de centroesquerda, os restantes são, respetivamente, de centro e de direita conservadora) e nenhum consegue resultados expressivos nas eleições em que participam. Em 2011, surge o PAN (primeiro Partido pelos Animais e pela Natureza, hoje Pessoas-Animais-Natureza), que, como o seu nome sugere, dá particular importância às questões ambientais e animalistas. Tratando-se de um partido que, pelo menos em 2015, se aproxima mais da esquerda do que da direita (LOBO, SANTANA-PEREIRA e SANCHES, 2015), não é um partido de esquerda radical. Na véspera das eleições europeias de 2014, surgem o Livre (que em 2015 se apresenta às eleições legislativas como Livre/Tempo de Avançar), resultante de uma cisão no seio do BE e encabeçado pelo eurodeputado Rui Tavares, e o MAS (Movimento Alternativa Socialista), que resulta também, em certa medida, de um afastamento de alguns elementos do BE, nomeadamente dos que haviam constituído a FER/Ruptura. Ambos são partidos de esquerda radical. Por fim, dos quatro novos partidos que são reconhecidos pelo Tribunal Constituicional em 2015, a tempo de participarem nas legislativas de outubro - o PURP (Partido Unido dos Reformados e Pensionistas), o NC (Nós Cidadãos), o PDR (Partido Democrático Republicano) e o JPP (Juntos Pelo Povo) - nenhum é de esquerda radical, e nenhum elegerá deputados.

Concentremos agora a nossa análise na natureza e no percurso dos dois partidos de esquerda radical que surgiram nos últimos anos: Livre e MAS. Em 2014/2015, em comparação com um BE indisponível para colaboração com o PS, o Livre distingue-se pela defesa de entendimentos alargados à esquerda. Os resultados obtidos pelo partido nas europeias de 2014 (71.602 votos, correspondentes a 2,2 por cento) não permitiram a eleição de um eurodeputado, mas criaram a expectativa de que o Livre conseguisse representação ao nível nacional nas eleições de 2015, nomeadamente nos círculos de Lisboa (onde obteve 3,6 por cento dos votos) e Porto (onde recebeu 2 por cento dos votos) (FREIRE e SANTANAPEREIRA 2015). De facto, nas eleições legislativas, o maior número de assentos parlamentares em jogo (230 na Assembleia da República vs. 21 no Parlamento Europeu) e a existência de círculos eleitorais de elevada magnitude (Lisboa elege 47 deputados e o Porto 39) tornam a eleição de deputados por parte de partidos pequenos mais fácil. 
No entanto, isto não veio a acontecer. Em outubro de 2015, o Livre/Tempo de Avançar conseguiu atrair menos de 1 por cento dos votos ao nível nacional, sendo que nem no círculo em que os resultados foram mais substanciais (Lisboa: 1,3 por cento dos votos) conseguiu eleger um deputado. Uma proporção de votos tão baixa não era esperada, olhando quer para os resultados que o partido obtivera em 2014, quer para as sondagens de intenção de voto nas legislativas, que apontavam para que o partido obtivesse cerca de 2 por cento. ${ }^{10}$ Alguns fatores internos, associados a alguma falta de estruturação e de capacidade de mobilização por parte do partido, bem como a uma mensagem demasiado focada em questões de estratégia, poderão estar na base deste resultado modesto. No entanto, acima de tudo terá sido o espantoso crescimento do $\mathrm{BE}$ (com quem o partido partilha várias perspetivas em termos programáticos), e algumas das razões subjacentes ao mesmo, a esvaziar o Livre/Tempo de Avançar de eleitores. O crescimento do BE começa a tomar forma ao longo do mês de setembro de 2015 e terá sido fomentado por uma mudança de estratégia das suas lideranças, que começam a declarar-se disponíveis para um entendimento com o PS, num panorama em que era pouco provável que este último conseguisse uma maioria absoluta dos votos (ou até mesmo uma vitória) em outubro. De um certo ponto de vista, o BE, ao abandonar uma postura de oposição perene, que poderá ter estado na origem dos seus péssimos resultados eleitorais de 2011 (legislativas) e 2014 (europeias), demonstrando-se disponível para entendimentos com o PS, acabou por neutralizar uma das características distintivas do Livre/Tempo de Avançar. Ademais, este último terá pecado por algum atraso na concretização desta ideia: a proposta pré-eleitoral de entendimento com o PS, PCP/PEV e BE só foi tornada pública no dia 1 de outubro, três dias antes das eleições e semanas após o famoso debate em que Catarina Martins, figura de topo do BE, se declarou disponível para negociar um entendimento com o PS de António Costa. Para além disso, em comparação com o BE, o Livre/Tempo de Avançar usufruiu de uma menor exposição mediática, quer nos noticiários, ${ }^{11}$ quer em termos de participação em debates ao longo do período de pré-campanha e de campanha. ${ }^{12}$

No que diz respeito ao MAS, a sua estrada tem sido mais tortuosa e os seus resultados muito pouco expressivos. Em termos programáticos, destaca-se por um grande extremismo em relação a outros partidos de esquerda radical, nomeadamente no que diz respeito à

${ }^{10}$ Ver as estimativas de resultados eleitorais, baseadas em todas as sondagens publicadas nos media, em www.popstar.pt.

${ }^{11}$ Numa análise de conteúdo das peças sobre as eleições transmitidas pelos telejornais durante o período de campanha, que realizei com Susana Rogeiro Nina, verifiquei que o Livre/Tempo de Avançar era referido em apenas 9 por cento das peças transmitidas nos três canais generalistas, enquanto o BE era alvo de referência em 40 por cento das peças. Os dados podem ser disponibilizados mediante pedido expresso.

${ }^{12} \mathrm{O}$ BE participa em 4 debates transmitidos em prime time em canais noticiosos. O Livre/Tempo de Avançar só participa num debate. 
dimensão europeia. O partido assume um anti-europeísmo que o aproxima bastante do PCP/PEV e do PCTP-MRPP. Em 2014, os slogans do partido transmitiam ideias como "Prisão para quem roubou e endividou o país" ou "O Euro afunda o país". ${ }^{13}$ A mensagem não agradou: o MAS foi o quarto partido menos votado nas europeias de maio de 2014, tendo conseguido menos de 13 mil votos, correspondentes a 0,4 por cento dos votos expressos naquela eleição. A estratégia do partido passou então por uma coligação com o PTP, denominada Agir (PTP-MAS) e encabeçada pela jovem e mediática Joana Amaral Dias, também ela ex-deputada eleita pelo BE (2002-2005). A estratégia não foi vencedora: a campanha foi marcada por fait divers (fotografias da líder grávida e seminua na capa de algumas revistas, conferências de imprensa destinadas a anunciar quem a substituiria no parlamento após o parto, um enorme atraso na divulgação do programa eleitoral). ${ }^{14}$ Os resultados eleitorais foram péssimos - cerca de 21 mil votos (0,4 por cento), menos 14 mil votos que os obtidos separadamente por MAS e PTP nas europeias de 2014.

Olhemos agora para estes partidos como um bloco, e estabeleçamos uma comparação com o que ocorre na Espanha e na Grécia. MARCH (2012) acredita que seria de esperar que a situação socioeconómica vivida pela União Europeia constituísse uma plataforma fértil de reemergência e florescimento da esquerda radical europeia. $\mathrm{Na}$ sua ótica, a crise do neoliberalismo e as políticas de austeridade postas em prática em vários países europeus levaram ao aumento da desigualdade, desconfiança e da insatisfação com a democracia, abrindo assim espaço para a possibilidade do aparecimento ou crescimento de partidos de esquerda radical que viessem liderar um levantamento populista contra o status quo político (MARCH, 2012).

Contudo, em Portugal, os benefícios eleitorais da crise económica e financeira para a esquerda radical foram escassos, pelo menos até agora. No Quadro 1, apresentam-se os resultados dos partidos de esquerda radical nos últimos 15 anos em três países: Portugal, Espanha e Grécia. Os resultados da esquerda radical são confrontados com os do principal partido de centro-esquerda e com os dos restantes partidos no espetro político nacional. Como podemos ver, em Portugal há, ao longo dos últimos 15 anos, uma tendência errática por parte da esquerda radical; dada a estabilidade eleitoral do PCP (que o distingue, aliás, dos partidos comunistas grego e espanhol, cujos resultados desde 1989 são mais instáveis e, em grande medida, mais modestos), isto deve-se essencialmente aos resultados do BE, que vai crescendo até 2009, sofre uma dura derrota em 2011 e regressa fortalecido (ma non troppo) em 2015.

\footnotetext{
${ }^{13}$ Ver o programa eleitoral e os cartazes do partido em http://www.mas.org.pt/

${ }^{14} \mathrm{O}$ programa é apresentado em 16 de setembro, cerca de 3 semanas antes das eleições.
} 
Outra característica distintiva do caso português é o relativo equilíbrio entre os resultados do PS e da esquerda radical como um todo - com exceção de 2009, quando o PS sobe, a esquerda radical sobe também; quando o PS perde votos, o mesmo ocorre com o conjunto dos partidos à sua esquerda. Ou seja, a variabilidade nos resultados dos partidos de esquerda parece resultar de viragens à esquerda ou à direita no eleitorado do centro mais do que em massivas transferências de votos dentro deste bloco. De facto, em Portugal, a volatilidade eleitoral inter-bloco (i.e., transferências de votos da esquerda para a direita e vice-versa, entre eleições) é, por norma, maior que a volatilidade intra-bloco ideológico (LISI 2015).

\section{Quadro 1 - O crescimento eleitoral da esquerda radical nas novas democracias da} Europa do Sul (2000-2015)

\begin{tabular}{|c|c|c|c|c|c|}
\hline & $\begin{array}{c}\text { Ano } \\
\text { eleitoral }\end{array}$ & $\begin{array}{l}\text { Esquerda } \\
\text { Radical* }\end{array}$ & $\begin{array}{c}\text { Centro- } \\
\text { Esquerda** }\end{array}$ & $\begin{array}{l}\text { Outros Partidos, } \\
\text { Brancos e Nulos }\end{array}$ & $\begin{array}{c}\text { Taxa de } \\
\text { abstenção }\end{array}$ \\
\hline \multirow[t]{5}{*}{ Portugal } & 2002 & 10,5 & 37,8 & 51,7 & 38,5 \\
\hline & 2005 & 14,8 & 45 & 40,2 & 35,7 \\
\hline & 2009 & 18,7 & 36,6 & 44,7 & 40,3 \\
\hline & 2011 & 14,3 & 28 & 57,7 & 42 \\
\hline & 2015 & 20,7 & 32,3 & 47 & 44,2 \\
\hline \multirow[t]{5}{*}{ Espanha } & 2000 & 5,6 & 34,2 & 60,3 & 31,3 \\
\hline & 2004 & 5,1 & 42,6 & 52,4 & 24,3 \\
\hline & 2008 & 3,9 & 43,9 & 51,1 & 24,7 \\
\hline & 2011 & 7 & 28,8 & 64,2 & 31,1 \\
\hline & 2015 & 24,5 & 22 & 51,5 & 26,8 \\
\hline \multirow[t]{8}{*}{ Grécia } & 2000 & 8,7 & 43,8 & 47,5 & 25,0 \\
\hline & 2004 & 9,3 & 40,5 & 50,2 & 23,4 \\
\hline & 2007 & 13,2 & 38,1 & 48,7 & 25,9 \\
\hline & 2009 & 12,1 & 43,9 & 44 & 29,1 \\
\hline & 2012-M & 25,3 & 13,2 & 61,5 & 34,9 \\
\hline & 2012-J & 31,4 & 12,3 & 56,3 & 37,5 \\
\hline & 2015-J & 41,8 & 4,7 & 53,5 & 35,4 \\
\hline & $2015-S$ & 41 & 6,3 & 52,7 & 43,4 \\
\hline
\end{tabular}

Fonte: TSIRBAS (2015) www.cne.pt, http://elpais.com/, www.idea.int Notas:

*Em Portugal: BE, PCP (coligação CDU), PCTP-MRPP e, em 2015, LIVRE e MAS. Em Espanha, Esquerda Unida, Partido Comunista dos Povos da Espanha e, em 2015, Podemos (excluem-se os partidos nacionalistas de esquerda, como o Esquerda Republicana da Catalunha). Na Grécia: Partido Comunista Grego (KKE), Coligação Esquerda e Progresso (SYN), e, a partir de 2004, SYRIZA.

** Em Portugal: PS; na Grécia: PASOK (em setembro de 2015 coligado com o DIMAR); na Espanha: PSOE.

Como vemos no Quadro 1, o que acontece em Espanha e na Grécia é bastante distinto.

Em Espanha, o bloco de partidos de esquerda radical é eleitoralmente muito fraco durante quase todo o período, e o ponto de viragem dá-se com o Podemos, que, em dezembro de 2015, consegue ficar lado a lado com o PSOE. Já na Grécia há um crescimento modesto da esquerda radical entre 2000 e 2009, que não é acompanhado por perdas por parte do PASOK. 
No entanto, nas quatro eleições que ocorrem depois do primeiro resgate, há um crescimento eleitoral considerável do bloco de partidos mais à esquerda (devido quase totalmente ao crescimento do SYRIZA) e um gradual desaparecimento do PASOK. Hoje em dia, o PASOK é um dos partidos eleitoralmente menos relevantes no panorama político grego.

\section{PORQUE É QUE NÃO HÁ UM PODEMOS OU UM SYRIZA EM PORTUGAL?}

Nos próximos parágrafos, elencam-se as características distintivas do contexto político e económico recente que podem ajudar a explicar porque éque em Portugal não se assistiu, após o início da crise, à criação de um novo partido de esquerda radical com discurso populista, eleitoralmente bem-sucedido, como o Podemos em Espanha (KIOUPKIOLIS, 2016), ou o crescimento exponencial de uma força política desta natureza já presente no sistema partidário, como acontece na Grécia com o SYRIZA (STAVRAKAKIS e KATSAMBEKIS, 2014). O propósito é o de elencar os principais fatores identificados no debate público sobre a ausência de um fenómeno deste tipo em Portugal ${ }^{15}$, apresentando-os de forma sistemática, qualificada e confrontando-os, sempre que possível, com dados empíricos. Os fatores aqui abordados dizem respeito a uma maior resiliência do centro-esquerda em Portugal, à existência de uma esquerda radical forte antes da crise, à menor politização dos eleitores portugueses, a um menor impacto da crise nos níveis de confiança nas instituições políticas, e a um menor choque económico produzido pela crise propriamente dita e pelas medidas de austeridade.

A primeira característica distintiva do caso português (neste caso em relação à Grécia, e menos em relação à Espanha), tem a ver com o estatuto dos partidos de centro-esquerda no momento de implementação das medidas de austeridade no âmbito de programas de ajustamento acordados com a troika. Ao contrário do que aconteceu na Grécia, em que o PASOK, sozinho ou coligado com o partido de direita ND, esteve sempre associado às medidas de austeridade implementadas pelo governo no quadro do programa de ajustamento financeiro, em Portugal a substituição do PS pelo PSD e CDS-PP na liderança do governo em meados de 2011 permitiu que os socialistas não fossem associados à implementação de medidas austeritárias, que são fortemente incongruentes com a bagagem ideológica de um

\footnotetext{
15 Ao longo do ano de 2015, este foi um tópico muito debatido na esfera pública. Veja-se, por exemplo, os artigos nos jornais Diário de Notícias de 20 de janeiro de 2015 (http://www.dn.pt/globo/interior/porque-e-quena-grecia-ha-syriza-e-em-portugal-nao-4351168.html) ou Público de 15 de março de 2015 (https://www.publico.pt/politica/noticia/o-envelhecimento--a-corrupcao-o-pcp-e-abril-preservaram-o-sistemapolitico-1689173).
} 
partido social democrata. As mudanças de liderança do PS também ajudaram a cortar as amarras com o passado, nomeadamente com a governação entre 2009 e 2011. Isto poderá ter sido favorável ao PS, que se consegue afastar de um quadro de medidas políticas cuja implementação dificilmente seria perdoada pelo seu eleitorado. Esta terá, aliás, sido uma estratégia consciente por parte do partido nos últimos tempos. Basta ler os jornais de 2015 para verificar que o PS, enquanto recusava encostamentos ao SYRIZA ${ }^{16}$, desejava ao máximo evitar uma temida pasokização. ${ }^{17}$ Em suma, se o principal partido de centro-esquerda dá sinais de resiliência, há menos espaço para alternativas políticas de esquerda ou de esquerda radical, mesmo num contex to em que a volatilidade intra-bloco é tradicionalmente baixa.

A punição do centro-esquerda pela implementação de medidas de austeridade pode ser função da incongruência destas medidas com o seu programa ideológico, mas, no caso grego, o clientelismo é também um fator a considerar. Em particular, acredita-se que a sobrevivência dos partidos gregos era particularmente ameaçada pela crise financeira, visto que as medidas de austeridade financeira significavam ter de colocar um ponto final nas relações clientelísticas com o seu eleitorado, porque restringiam a sua capacidade de controlar os orçamentos de maneira a poder recompensar os seus «clientes» (AFONSO, ZARTALOUDIS e PAPADOPOULOS 2015). Nas palavras dos autores: "na Grécia, onde os partidos se baseiam muito nestas ligações clientelísticas, as reformas austeritárias foram marcadas por uma série de conflitos e desentendimentos entre os principais partidos, e a uma mudança fundamental do sistema de partidos. Ao contrário, em Portugal, onde os partidos se apoiam menos nestas estratégias clientelísticas, as reformas austeritárias foram mais consensuais porque ameaçavam menos a base eleitoral dos principais partidos" (p. 315, nossa tradução). Dada a inevitabilidade da implementação de medidas de austeridade, não é que admirar que um grande partido de centro-esquerda grego como o PASOK tenha visto as fileiras do seu eleitorado esvaziar-se.

Uma segunda característica distintiva é a existência, nos anos que antecedem a crise, de uma esquerda radical forte em Portugal e mais modesta em Espanha e, em certa medida, na Grécia. Falamos, em concreto, de um partido comunista com grande capacidade de mobilização do seu eleitorado, o que lhe tem permitido usufruir de uma grande estabilidade em termos de resultados eleitorais nos últimos 25 anos (próximo dos 10 por cento; ainda que

\footnotetext{
${ }^{16}$ Esta ideia foi discutida em várias ocasiões: por exemplo, em julho de 2015, no contexto do referendo grego relativo ao acordo com a troika para um novo resgate financeiro (http://observador.pt/2015/07/06/costa-o-psnao-e-o-syriza-nao-ao-grexit-e-sim-a-um-acordo/) ou no rescaldo das legislativas de 4 de outubro de 2015 (http://www.jornaldenegocios.pt/economia/detalhe/antonio_costa_o_ps_nao_e_o_syriza.html).

17 Ver, a título de exemplo, o seguinte artigo no Observador, publicado imediatamente após as eleições: http://observador.pt/2015/10/07/costistas-preocupados-com-a-pasokizacao-do-ps/
} 
antes da queda do Muro de Berlim, os resultados eleitorais do PCP fossem significativamente mais altos, situando-se entre os 12 e os 18 por cento). Falamos também da existência de um partido afirmado e bem-sucedido que, do ponto de vista ideológico, tem bastante em comum com o Podemos e com o SYRIZA, com exceção do discurso populista - o BE. A existência destes partidos, cujo potencial crescimento eleitoral é limitado pelas características do seu eleitorado ou pela escolha de estratégias nem sempre coerentes ou populares entre os seus eleitores, reduz, de alguma maneira, a possibilidade de um novo partido com agendas similares crescer eleitoralmente de forma substancial, em particular quando não há um colapso, ou pasokização, do centro-esquerda. Estes partidos, em particular o PCP mas também o BE, foram ainda capazes de canalizar o euroceticismo decorrente de uma má avaliação da intervenção da União Europeia na gestão da crise, devido ao seu historial de eurocepticismo flagrante ou difuso antes da eclosão da crise das dívidas soberanas.

Um terceiro fator está ligado à distinta cultura política nos três países. Apesar de algumas semelhanças entre os contextos gregos, espanhol e português, existem alguns aspetos distintivos. Em primeiro lugar, em eleições legislativas, as taxas de abstenção tendem a ser mais elevadas em Portugal do que na Grécia (com a exceção da eleição de setembro de 2015) ou em Espanha (ver Quadro 1) - nem que seja porque na Grécia o voto é obrigatório (ainda que as medidas de dissuasão e punição da abstenção sejam pouco eficazes). Por outro lado, como defende AFONSO (2015), os eleitores portugueses são pouco politizados quando comparados com os espanhóis, italianos ou gregos. Testámos este argumento com dados recolhidos pelo European Election Study de 2014, e o que observámos corrobora a análise de AFONSO (2015): enquanto 47 por cento dos gregos e 39 por cento dos espanhóis afirmam interessar-se por política (muito ou moderadamente), apenas 30 por cento dos portugueses expressam a mesma posição. Por outro lado, enquanto 75 por cento dos portugueses consideram que a política é por vezes tão complicada que é difícil perceber o que se passa, apenas 56 por cento dos gregos exprimem esta dificuldade (o número para a Espanha é 70 por cento). Ademais, enquanto 18 por cento dos espanhóis afirmam ter participado numa manifestação pelo menos uma vez em finais de 2013/início de 2014, apenas 10 por cento dos portugueses terá feito o mesmo (na Grécia, o número é 12 por cento). Tudo isto aponta para um quadro de menor politização em Portugal em relação à Grécia e Espanha. Nas palavras de AFONSO (2015), o que terá acontecido é que os eleitores insatisfeitos mas politizados - que parecem existir em maior número em Espanha e na Grécia que em Portugal - escolhem votar em partidos de protesto, entre os quais encontramos a esquerda radical populista (uma 
estratégia de voz), enquanto eleitores insatisfeitos mas apáticos optam pela não mobilização ou abstenção (uma estratégia de saída ou afastamento do processo político).

A evolução dos níveis de confiança nos partidos é também distinta nestes três países. De acordo com os dados discutidos por BOSCO e VERNEY (2012), o impacto da crise na confiança que os cidadãos têm nos partidos políticos foi consideravelmente mais forte em Espanha e na Grécia do que em Portugal. Em 2008, 40 por cento dos espanhóis confiavam nos partidos, enquanto em 2011 só 12 por cento diziam o mesmo; na Grécia, os valores são de 17 por cento em 2008 e 5 por cento em 2011 - uma descida vertiginosa, ainda que não tão acentuada quanto a observada no caso espanhol. Já Portugal, que parte em 2008 com uma taxa de confiança nos partidos muito baixa (19 por cento), apresenta uma quebra modesta (em 2011, 14 por cento). Assim, poderíamos argumentar que em contextos em que há uma quebra acentuada de confiança nos partidos políticos tradicionais, novos partidos de esquerda radical têm maiores chances de crescimento eleitoral.

Por fim, razões de natureza económica. Um dos motivos da diferença observada entre os casos português, espanhol e grego poderá ter a ver com a magnitude da crise. O impacto da crise e do que se seguiu levou a um aumento exponencial do desemprego, a uma quebra astronómica do PIB e à erosão do nível de vida de muitos cidadãos. No entanto, em Portugal, apesar de a gravidade da crise é inegável, o seu impacto não é comparável com o que ocorre na Grécia (FREIRE et al., 2014); ademais, no caso português a intensidade da austeridade nunca atingiu os níveis gregos. A expressão "Portugal não é a Grécia" foi um leitmotiv nestes últimos anos, usado à esquerda e à direita. ${ }^{18}$ Para além disso, como bem lembra AFONSO (2015), antes da crise das dívidas soberanas Portugal já estava num período de estagnação económica, que começara com a entrada no euro - ficaram famosas as declarações do primeiro-ministro José Manuel Durão Barroso ("o país está de tanga") ${ }^{19}$ em abril de 2002. Já a Grécia e a Espanha tiveram um boom económico na década que antecedeu o eclodir da crise das dívidas soberanas (AFONSO, 2015). Por outras palavras, os portugueses já viviam em crise moderada antes da crise da dívida, com medidas pontuais de redução da despesa decorrente dos défices crónicos, pelo que a mudança não foi tão súbita e violenta quanto noutros contextos. Enquanto em Portugal se passa de uma situação má para uma situação terrível, nos outros países passa-se de uma situação boa para uma situação terrível. O choque

18 Por exemplo, pelo vice primeiro-ministro Paulo Portas, em julho de 2015 (http://www.dn.pt/politica/interior/portas-reafirma-portugal-nao-e-a-grecia--4661683.html) e por Mário Centeno, responsável pelo programa económico do PS e ministro das Finanças do governo PS a partir de novembro de 2015 (http://sol.pt/noticia/479891/-Portugal-nao-sera-a-Grecia-garante-Centeno).

19 Ver, por exemplo: https://www.publico.pt/politica/noticia/durao-barroso-diz-que-socialistas-deixaramportugal-de-tanga-130198

Oficina do Historiador, Porto Alegre, EDIPUCRS, v. 9, n. 1, jan./jun. 2016 
é, assim, necessariamente maior para os gregos que para os portugueses - e o impacto político da crise (nomeadamente em termos de criação de novos partidos e/ou aumento do apoio eleitoral à esquerda radical) também.

\section{NOTAS FINAIS}

Em 2012, FREIRE sublinhava o facto de que, apesar de muito distintos, o PCP e o BE eram bastante similares no que diz respeito à sua posição relativa à participação em soluções governamentais. Ambos os partidos se demonstravam pouco disponíveis para tal, apesar dos incentivos que o contexto fornecia para um entendimento com o PS - algo que teria provavelmente sido muito apreciado pelo centro-esquerda nos tumultuosos meses que precederam a queda do segundo executivo Sócrates e a formalização do pedido de resgate em 2011. No entanto, no rescaldo das eleições de 4 de outubro de 2015, em que nem o PS nem a coligação PSD/CDS-PP conseguem uma maioria dos assentos na Assembleia da República, tanto o BE como o PCP (e os Verdes) se demonstram disponíveis para viabilizar um governo do PS. O modelo que acaba por ser adotado não é de uma coligação pós-eleitoral de esquerda, mas aproxima-se do ideal-tipo de parlamentarismo de contrato ${ }^{20}$ comum em países do norte da Europa, como a Suécia (DE GIORGI e SANTANA-PEREIRA, 2016). Após um processo de negociação relativamente curto, o PS estabeleceu acordos escritos com estes dois partidos, no sentido da viabilização do seu governo minoritário no parlamento. Isto significa que, pela primeira vez desde 1976, a extrema-esquerda tem, ainda que indiretamente, alguma responsabilidade pelas ações do governo. Em Portugal, fala-se do derrube do Muro de Berlim que mantinha a extrema-esquerda numa posição de oposição virtualmente perpétua. ${ }^{21}$ Cerca de seis meses após a indigitação de António Costa como primeiro-ministro, é ainda cedo para saber qual será o impacto desta decisão da esquerda radical nas suas perspetivas futuras em eleições de primeira ordem. De qualquer maneira, a "geringonça" (termo depreciativo usado pelos críticos da solução governamental e ocasionalmente reproposto com ironia pela esquerda) já se mostrou resistente às tensões resultantes de um péssimo resultado do

\footnotetext{
20 O parlamentarismo de contrato é uma situação em que governos que são formalmente minoritários desenvolvem relações institucionalizadas com os partidos que os apoiam no parlamento de tal forma que quase passam a ser governos maioritários. A institucionalização passa pela existência de acordos escritos explícitos e públicos que formalizam um entendimento que vai além de uma área de políticas públicas ou um conjunto reduzido de medidas (AYLOTT e BERGMAN, 2004; BALE e BERGMAN, 2006).

${ }^{21}$ Ver, por exemplo, as declarações de Costa em outubro de 2015, em: http://www.dn.pt/portugal/interior/costae-como-deitar-abaixo-o-resto-do-muro-de-berlim-4833408.html
} 
candidato comunista e um ótimo resultado da candidata do BE nas eleições presidenciais de janeiro de 2016.

Curiosamente, no rescaldo das eleições espanholas de dezembro de 2015, em que nenhum dos partidos conseguiu um resultado que lhe permitisse governar sozinho, cogitou-se a hipótese de implementar uma solução similar à portuguesa, com o Podemos a viabilizar um governo minoritário do PSOE. Isto não veio a acontecer, e novas eleições foram marcadas para o verão de 2016. Se o equilíbrio de forças dos partidos não for distinto do cristalizado pelos eleitores em 20 de dezembro, a "solução à portuguesa" pode voltar a ser colocada em cima da mesa. O parlamentarismo de contrato parece querer rumar ao sul.

\section{REFERENCIAS}

AFONSO, Alexandre. Why the next Portuguese election will not see the surge of a left-wing challenger like Podemos or Syriza. Entrada no Blogue da LSE EUROPP: European Politics and Policy. Disponível em: http://blogs.lse.ac.uk/europpblog/2015/08/25/why-the-nextportuguese-election-will-not-see-the-surge-of-a-left-wing-challenger-like-podemos-or-syriza/. Acesso em 6 de janeiro de 2016. 2015.

AFONSO, Alexandre, ZARTALOUDIS, Sotirios e PAPADOPOULOS, Yannis. How party linkages shape austerity politics: Clientelism and fiscal adjustment in Greece and Portugal

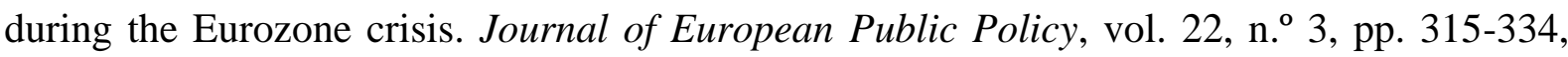
2015.

ALMEIDA, Pedro Tavares, e FREIRE, André. Two overwhelming victories of the left: The 2004 European Election and the 2005 Legislative Election. South European Society and Politics, vol. 10, n. ${ }^{\circ}$ 3, pp. 451-464, 2005.

AYLOTT, Nicholas, e BERGMAN, Torbjörn. Almost in government, but not quite: The Swedish Greens, bargaining constraints and the rise of contract parliamentarism. ECPR Joint Sessions, Uppsala, Sweden, 2004.

BALE, Tim, e BERGMAN, Torbjörn. Captives no longer, but servants still? Contract parliamentarism and the new minority governance in Sweden and New Zealand. Government and Opposition, vol. 41, n. ${ }^{\circ}$ 3, pp. 422-449, 2006.

BARTELS, Larry. Elections in hard times. Public Policy Research, vol. 19, n. ${ }^{\circ}$ 1, pp. 44-50, 2012. 
BELLUCCI, Paolo. The political consequences of blame attribution for the economic crisis in the 2013 Italian national election. Journal of Elections, Public Opinion and Parties, vol. 24, n. 2 , pp. 243-263, 2014.

BOSCO, Anna, e VERNEY, Susannah. Electoral epidemic: The political cost of economic crisis in Southern Europe, 2010-2011. South European Society and Politics, vol. 17, n. ${ }^{\circ}$ 2, pp. 129-154, 2012.

DE GIORGI, Elisabetta, e SANTANA-PEREIRA, José. The 2015 Portuguese legislative election: Widening the coalitional space and bringing the extreme left in. South European Society and Politics, online first, 2016. DOI: 10.1080/13608746.2016.1181862.

DIAMANTI, Ilvo. The 5 Star Movement: A political laboratory. Contemporary Italian Politics, vol. 6, n. ${ }^{\circ}$ 1, pp. 4-15, 2014.

ESPÍRITO SANTO, Paula. The 2009 Portuguese parliamentary elections. Electoral Studies, vol. 29, n. ${ }^{\text {o }}$ 2, pp. 279-281, 2010.

FERNANDES, Jorge M., e SANTANA PEREIRA, José. Os programas eleitorais das eleições europeias: Análise preliminar das principais dimensões de competição. Relações Internacionais, vol. 41, pp. 81-95, 2014.

FREIRE, André. A esquerda radical em Portugal. In MARCH, Luke e FREIRE, André (Orgs.) A Esquerda Radical em Portugal e na Europa: Marxismo, Mainstream ou Marginalidade? Vila do Conde: QuidNovi, 2012, pp. 105-243.

FREIRE, André, LISI, Marco, ANDREADIS, Ioannis, e VIEGAS, José Manuel Leite. Political representation in bailed-out Southern Europe: Greece and Portugal compared. South European Society and Politics, vol. 19, n. ${ }^{\circ}$ 4, pp. 413-433, 2014.

FREIRE, André, LOBO, Marina Costa, e MAGALHÃES, Pedro. Portugal at the Polls in 2002. Lanham: Lexington Books, 2007.

FREIRE, André, e SANTANA PEREIRA, José. Portugal, 2011: Portugal 2011 : une victoire de la droite néolibérale et une défaite de la gauche. Pôle Sud, n. ${ }^{\circ}$ 35, pp. 157-166, 2011.

FREIRE, André, e SANTANA PEREIRA, José. Economic voting in Portugal, 2002-2009. Electoral Studies, vol. 31, n. ${ }^{\circ}$ 3, pp. 506-512, 2012.

FREIRE, André, e SANTANA PEREIRA, José. More second order than ever? The 2014 European Parliament elections in Portugal. South European Society and Politics, vol. 20, n. ${ }^{\circ}$ 3, pp. 381-401, 2015.

GOMEZ, Raul, MORALES, Laura, e RAMIRO, Luis. Varieties of radicalism: Examining the diversity of radical left parties and voters in Western Europe. West European Politics, vol. 39, n. ${ }^{\circ}$, pp. 351-379, 2016. 
HERNANDEZ, Enrique, e KRIESI, Hanspeter. The electoral consequences of the financial and economic crisis in Europe. European Journal of Political Research, vol. 55, n. ${ }^{\circ}$, pp. 203-224, 2016.

KIOUPKIOLIS, Alexandros. Podemos: the ambiguous promises of left-wing populism in contemporary Spain. Journal of Political Ideologies. DOI: 10.1080/13569317.2016.1150136 LEWIS-BECK, Michael, e PALDAM, Martin. Economic voting: An introduction. Electoral Studies, vol. 19, n. ${ }^{\circ}$-3, pp. 112-121, 2000.

LEWIS-BECK, Michael, e STEGMAIER, Mary. Economic determinants of electoral outcomes. Annual Review of Political Science, vol. 3, pp. 183-219, 2000.

LISI, Marco. As Eleições Legislativas no Portugal Democrático, 1975-2015. Lisboa: Assembleia da República, 2015.

LOBO, Marina Costa, SANTANA PEREIRA, José, e SANCHES, Edalina. Relatório síntese da Bússola Eleitoral, 2: A política económica vista pelos eleitores. Unpublished report. Disponível online em: http://marinacostalobo.pt/webwp/wpcontent/uploads/2014/11/relat\%C3\%B3rio-02-da-Bussola-Eleitoral1.pdf, Acesso em 15 de dezembro de 2016, 2015.

MAGALHÃES, Pedro. After the bailout: Responsibility, policy, and valence in the Portuguese legislative election of June 2011. South European Society and Politics, vol. 17, n. ${ }^{\circ}$ 2, pp. 309-327, 2012.

MAGALHÃES, Pedro C. Introduction: Financial Crisis, Austerity and Electoral Politics. Journal of Elections, Public Opinion and Parties, vol. 24, n. ${ }^{\circ}$ 2, pp. 125-133, 2014a.

MAGALHÃES, Pedro C. The elections of the great recession in Portugal: Performance voting under a blurred responsibility for the economy. Journal of Elections, Public Opinion and Parties, vol. 24, n. ${ }^{\circ}$ 2, pp. 180-202, 2014b.

MARCH, Luke. Os partidos europeus da esquerda radical após a crise: Marxismo, mainstream ou marginalidade? Em MARCH, Luke e FREIRE, André (Orgs.), A Esquerda Radical em Portugal e na Europa: Marxismo, Mainstream ou Marginalidade? Vila do Conde: QuidNovi, 2012, pp. 25-104.

MARSH, Michael, e MIKHAYLOV, Slava. A conservative revolution: The electoral response to economic crisis in Ireland. Journal of Elections, Public Opinion and Parties, vol. 24, n. ${ }^{\circ}$ 2, pp. 160-179, 2014.

MARTÍN, Irene, e URQUIZO-SANCHO, Ignazio. The 2011 general election in Spain: The collapse of the Socialist Party. South European Society and Politics, vol. 17, n. ${ }^{\circ}$ 2, pp. $347-$ $363,2012$. 
ROMÃO, Filipe Vasconcelos. Podemos e Cuidadanos: O fim do bipartidarismo em Espanha? Relações Internacionais, vol. 45, pp. 81-95, 2015.

SANTANA PEREIRA, José. Portugal. In GAGATEK, Wojciech (org.), The 2009 Elections to the European Parliament: Country Reports. Florença: European University Institute (EBook), 2010, pp. 143-148.

SANTANA PEREIRA, José (2015). Eleições em tempos de crise: Austeridade, troika e a derrota anunciada do PS nas legislativas de 2011. In LISI, Marco (org.), As Eleições Legislativas no Portugal Democrático, 1975-2015. Lisboa: Assembleia da República, 2015, pp. 257-270.

STAVRAKAKIS, Yannis, e KATSAMBEKIS, Giorgos. Left-wing populism in the European periphery: the case of SYRIZA. Journal of Political Ideologies, vol. 19, n. ${ }^{\circ}$ 2, pp. 119-142, 2014.

TORCAL, Mariano. The incumbent electoral defeat in the 2011 Spanish national elections: The effect of the economic crisis in an ideological polarized party system. Journal of Elections, Public Opinion and Parties, vol. 24, n. ${ }^{\circ}$ 2, pp. 203-221, 2014.

TSATSANIS, Emmanouil, e TEPEROGLOU, Eftichia. Dealignment, de-legitimation and the implosion of the two-party system in Greece: The Earthquake election of 6 May 2012. Journal of Elections, Public Opinion and Parties, vol. 24, n. ${ }^{\circ}$ 2, pp. 222-242, 2014.

TSIRBAS, Yannis. The January 2015 parliamentary election in Greece: Government change, partial punishment and hesitant stabilisation. South European Society and Politics. DOI: 10.1080/13608746.2015.1088428, 2015.

VASSELAI, Fabricio, e MIGNOZZETTI, Umberto. The Impacts of International Economic Crises on the Succession of Incumbents in 55 Countries (1960-2011). APSA 2012 Annual Meeting Paper. Disponível em: http://ssrn.com/abstract=2108034, acesso em 15 de janeiro de 2016, 2012. 